Target Article: Why Imaginary Worlds? The psychological foundations and cultural evolution of fictions with imaginary worlds (Dubourg, E. \& Baumard, N.)

\title{
Not Just a Hijack: Imaginary Worlds Can Enhance Individual and Group-Level Fitness
}

\author{
Danica Wilbanks ${ }^{1 \dagger}$, Jordan W. Moon ${ }^{2}$, Brent Stewart ${ }^{3}$, Kurt Gray $^{1}$, Michael E. W. Varnum ${ }^{2}$
}

${ }^{1}$ University of North Carolina at Chapel Hill, Department of Psychology and Neuroscience

${ }^{2}$ Arizona State University, Department of Psychology

${ }^{3}$ University of British Columbia, Vancouver, Department of Psychology

†Correspondence should be addressed todanicaw@email.unc.edu

\begin{abstract}
Why has fiction been so successful over time? We make the case that fiction may have properties that enhance both individual and group level fitness by (a) allowing risk-free simulation of important scenarios, (b) effectively transmitting solutions to common problems, and (c) enhancing group cohesion through shared consumption of fictive worlds.
\end{abstract}

Soldiers often fight real battles against enemies, but they just as often fight pretend--or fictive--battles against imagined enemies. Generals imagine new scenarios and soldiers both think through them and act through them. One might be tempted to argue that these mere "war games" are a distraction from the real business of war--hijacking the minds of soldiers for silly diversions. But these scenarios have another name that reveal their true purpose: "readiness exercises." These exercises ready soldiers for the real business of war. They allow soldiers to practice their skills, be exposed to new scenarios, try new strategies in a (relatively) safe space, and bond and coordinate with their comrades. In war, fictive scenarios are not a distraction but crucial preparation for an uncertain world.

Not everyone fights battles, but each of us lives in an uncertain and sometimes dangerous world, where threats abound and people must constantly work to be prepared for the future. And yet, people around the world and through history spend countless hours consuming fiction? 
Why? Perhaps people are easily distracted and their systems are easily hijacked. Or perhaps it helps to think of fiction from a different perspective--not as mental parasites, but as "readiness exercises" for life.

We certainly agree with Dubourg and Boumard that imaginary worlds serve many purposes. Indeed, the examples cited in their review include conveying important lessons, spreading culturally valued information, and allowing the simulation of new scenarios. They argue, however, that these fictive worlds (and their success) can best be understood as effectively a hijack of an evolved motivational system to explore one's environment. Our take on the persistence and success of these imaginary worlds is somewhat different, namely we argue that fiction may have been so successful over time primarily because it may enhance fitness at both the individual and the group-level.

First, fiction extends phenotypic flexibility beyond the natural environment by preparing people for a wider range of situations than they might encounter in their normal environments. Fiction lets people explore new scenarios with minimal risk. Just as readiness exercises help soldiers prepare for battle, fiction enables people to explore a wide range of experiences in a risk-free 'life simulator.' For instance, fans of horror or "prepper" films may actually be better off once emergency strikes (Scrivner, Johnson, Kjeldgaard-Chistiansen, \& Clasen, 2021), and readers of Victorian novels might be better off when cooperative needs arise (Johnson, Carroll, Gottschall, \& Kruger, 2011). The stories parents tell to children might also transmit advice in a way that is memorable for the child (Mar \& Oatley, 2008), enabling humans during an especially vulnerable point in their development to learn about various dangers in a low risk fashion.

It may seem odd to argue that fiction helps to prepare us for the world, because the scenarios depicted are often more extreme than those encountered in everyday life. For example, fiction includes much more mortality than real life (Morin, Acerbi, \& Sobchuk, 2019). But this is actually the benefit of fiction - if fiction helps people prepare for high-stakes situations, one might expect overrepresentation of risky or dangerous scenarios. Thus by enabling individuals to learn about and prepare for events beyond those previously or frequently encountered, fiction may increase individuals' ability to successfully respond to future threats and opportunities in their environments.

Fiction is also packed with problem-solution scenarios. These scenarios give opportunities for people to practice challenges they may not otherwise experience in a relatively short time (Boyd, 2018). In the time it takes to read a book or watch a movie, the viewer has simulated more scenarios than they could have experienced in real life. This leads to our second point: fiction enables more efficient transmission of information, skills, and values than might be possible with other means. As Dubourg and Boumard note, fiction grabs our attention by focusing on the parts of life that we find most interesting while filtering out monotonous noise. Not only does this quality contribute to fiction's success, it also allows fiction to convey more relevant information than one could normally acquire and allows for the rapid spread of this 
shared information among group members. For example, people understand and recall stories better than expository texts (Mar et al., 2021), and social information better than asocial information (Mesoudi, Whiten, \& Dunbar, 2006). Further, stories often utilize repetition and social learning, both of which help people learn new skills (Silveira, 2021; Jiménez \& Mesoudi, 2019). We suggest that by rapidly spreading fitness relevant knowledge with high fidelity, the consumption of fiction should yield fitness benefits to both individuals and groups.

Finally, shared consumption of rich fictive worlds can unify groups and create shared realities and goals. This may enhance group cohesion and provide advantages in competition with other groups whose fictive worlds are less rich or absent. Fiction has been shown to increase prosociality (Johnson, 2012; Johnson et al., 2013; Smith et al., 2017). For example, a recent study of the Agta, a Filipino hunter-gatherer population, found that having good storytellers was associated with increased cooperation within groups (Smith et al, 2017). Fiction is especially apt at strengthening cultural norms because people emulate others they perceive as prestigious (Jiménez \& Mesoudi, 2019), and fans often admire fictional characters. Thus fiction may enhance group fitness through strengthening cooperation and a sense of shared identity within the group.

If we consider fiction as adaptive at multiple levels of selection, we may derive several novel predictions. 1) All other things being equal, individuals who consume more fiction might be better prepared to respond adaptively to rare events with high potential threat to survival. 2) All other things being equal, people may find potential interaction partners or mates who consume more fiction more appealing. 3) To the extent that fictive worlds enhance cooperation within groups, we would predict that richer fictive worlds may have proceeded increases in group size historically, and that cooperation-enhancing fiction might be especially common where societies face large-scale coordination challenges. 4) Societies where consumption of fiction is more common might have more unified responses to external threats.

\section{References}

Boyd, B. (2018). The evolution of stories: from mimesis to language, from fact to fiction. Wiley Interdisciplinary Reviews: Cognitive Science, 9(1), e1444.

Jiménez, Á. V., \& Mesoudi, A. (2019). Prestige-biased social learning: current evidence and outstanding questions. Palgrave Communications, 5(1), 1-12.

Johnson, D. R. (2012). Transportation into a story increases empathy, prosocial behavior, and perceptual bias toward fearful expressions. Personality and individual differences, 52(2), 150-155. 
Johnson, D. R. (2013). Transportation into literary fiction reduces prejudice against and increases empathy for Arab-Muslims. Scientific Study of Literature, 3(1), 77-92.

Johnson, D. R., Cushman, G. K., Borden, L. A., \& McCune, M. S. (2013). Potentiating empathic growth: Generating imagery while reading fiction increases empathy and prosocial behavior. Psychology of Aesthetics, Creativity, and the Arts, 7(3), 306.

Johnson, J. A., Carroll, J., Gottschall, J., \& Kruger, D. (2011). Portrayal of personality in Victorian novels reflects modern research findings but amplifies the significance of agreeableness. Journal of Research in Personalty, 45, 50-58.

Mar, R. A., Li, J., Nguyen, A. T., \& Ta, C. P. (2021). Memory and comprehension of narrative versus expository texts: A meta-analysis. Psychonomic Bulletin \& Review, 1-18.

Mar, R. A., \& Oatley, K. (2008). The function of fiction is the abstraction and simulation of social experience. Perspectives on Psychological Science, 3(3), 173-192.

Mesoudi, A., Whiten, A., \& Dunbar, R. (2006). A bias for social information in human cultural transmission. British Journal of Psychology, 97(3), 405-423.

Morin, O., Acerbi, A., \& Sobchuk, O. (2019). Why people die in novels: testing the ordeal simulation hypothesis. Palgrave Communications, 5(1), 1-10.

Scrivner, C, Johnson, J. A., Kjeldgaard-Christiansen, J, \& Clasen, M. (2021). Pandemic practice: Horror fans and morbidly curious individuals are more psychologically resilient during the COVID-19 pandemic. Personality and Individual Differences, 168, 110397.

Silveira Jr, A. S. (2021). The Power of Repetition. In Building and Managing High-Performance Distributed Teams (pp. 155-167). Apress, Berkeley, CA.

Smith, D., Schlaepfer, P., Major, K., Dyble, M., Page, A. E., Thompson, J., ... \& Migliano, A. B. (2017). Cooperation and the evolution of hunter-gatherer storytelling. Nature communications, 8(1), 1-9. 